\section{Mercuric chloride poisoning in a 23 month old child}

Mercuric chloride, also known as corrosive sublimate, is only slightly soluble in water. It is one of the most toxic mercury salts, the lethal dose for an adult being less than $0.4 \mathrm{~g}$. Renal failure, which results from necrosis of the proximal renal epithelium, has been successfully treated by haemodialysis in a 19 month old boy who ingested mercuric chloride powder, although in his case the local effect was relatively mild. ${ }^{1}$ We report on a 23 month old boy who suffered little renal damage but in whom the local reaction was severe.

\section{Case report}

A 23 month old boy ingested an unknown quantity of mercuric chloride powder (normally used for skin preparations) from a bottle that was on a low shelf in a chemist's shop. He was found with powder in his mouth and on his lips. Vomiting was immediately induced. Within five minutes his tongue and lips were swollen. On admission to hospital within an hour oedema and ulceration were so extensive that breathing was threatened, although tracheostomy was not necessary. He was treated with dimercaprol $6 \mathrm{mg} / \mathrm{kg}$ body weight intramuscularly every six hours for 48 hours, followed by half dosage for a further 48 hours. He was also treated with hydrocortisone with broad spectrum antibiotic cover to prevent oesophageal stricture. Activated charcoal was administered by nasogastric tube. On admission blood urea concentration was $8.7 \mathrm{mmol} / 1(52.3 \mathrm{mg} / 100 \mathrm{ml})$ and blood creatinine concentration normal at $43 \mu \mathrm{mol} / 1(486 \mu \mathrm{g} / 100 \mathrm{ml})$. Serial blood and mercury concentrations were assayed, and renal function was closely monitored (table).

Blood and urine mercury concentrations and blood urea and creatinine concentrations

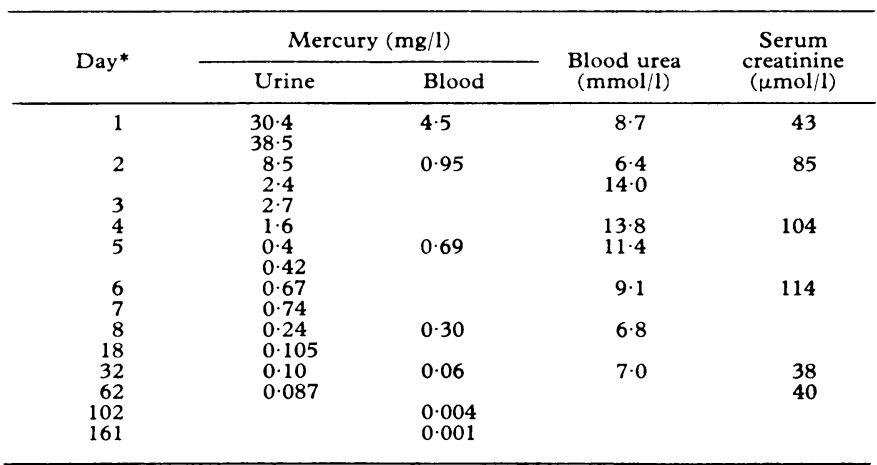

*Dimercaprol was given over days 1-4

Conversion: SI to traditional units-Urea: $1 \mathrm{mmol} / 1 \approx 6 \mathrm{mg} / 100 \mathrm{ml}$. Creatinine: $1 \mu \mathrm{mol} / 1 \approx 11.3 \mu \mathrm{g} / 100 \mathrm{ml}$

\section{Comment}

This boy exhibited considerable local reaction to the mercuric chloride powder and relatively little renal damage, unlike the child reported on previously. ${ }^{1}$ The blood concentration of mercury three hours after ingestion was $4.5 \mathrm{mg} / \mathrm{l}$, which with treatment fell to $0.95 \mathrm{mg} / \mathrm{l}$ after 24 hours. In the other case the earliest blood concentration reported was $1.92 \mathrm{mg} / \mathrm{l}$, but this was 48 hours after ingestion. ${ }^{1}$ By this time the child was in renal failure and chelation treatment had not, at that stage, been started. Prompt action by the mother in our case, who induced vomiting at the site of the incident, followed by immediate admission to hospital and early institution of treatment with dimercaprol may have minimised the possibility of renal effects.

The very high blood mercury concentration on admission fell rapidly as large amounts of mercury were excreted in the urine. Thereafter the amount of mercury excreted (day four onwards) showed little change, and we considered whether to give penicillamine to prevent renal damage. Renal function showed mild impairment, the highest blood urea concentration being $14 \mathrm{mmol} / 1(84 \mathrm{mg} / 100 \mathrm{ml})$ (day four) and the highest creatinine concentration $114 \mu \mathrm{mol} / \mathrm{l}$ $(1.3 \mathrm{mg} / 100 \mathrm{ml}$ ) (day six). We thought that monitoring renal function and blood and urine mercury concentrations while withholding penicillamine treatment was the correct course of action.

By day eight he was eating and swallowing soft foods without difficulty. He had residual oral gingivitis but no scarring of the oral mucosa. Subsequently, he fully recovered his normal renal function, but his blood mercury concentrations returned to normal only after more than 100 days. Early recognition of this potentially lethal poisoning and appropriate treatment saved this boy's life. Monitoring of blood and urinary mercury concentrations guided treatment and was invaluable in long term management.

We are grateful to the occupational health laboratory of the Health and Safety Executive, Cricklewood, London, for the blood mercury assays.

'Samuels ER, Heick HM, McLaine PN, Farant JP. A case of accidental inorganic mercury poisoning. F Anal Toxicol 1982;6:120-2.

(Accepted 1 August 1983)

Department of Paediatrics and Regional Toxicology Laboratory, Dudley Road Hospital, Birmingham B18 7QH

T STACK, MRCP, paediatric registrar

J G BISSENDEN, BM, MRCP, consultant paediatrician

G HOFFMAN, medical student

W B YEOMAN, FRIC, FRCPATH, director of regional toxicology laboratory

Correspondence to: Dr J G Bissenden.

\section{Allergic reaction to rubber chemicals in haemodialysis equipment}

Rubber components in connectors, tubing, and $\mathrm{O}$ rings are widely used in haemodialysis equipment. Some clinicians may not realise that an allergic reaction to these components may cause recurrent and distressing dermatitis.

\section{Case report}

A man aged 40 with congenital hypoplastic kidneys was first admitted with incipient renal failure and hypertension in 1976. Subsequently he had intermittent haemodialysis, generally three times a week. Renal transplantations in 1976, 1977, and 1981 were unsuccessful. In June 1982 he underwent parathyroidectomy with subcutaneous implantation of fragments of parathyroid in the right arm.

In November 1979 he developed an itchy eczematous rash on the hands. Patch testing in February 1980 showed a positive reaction to $2 \%$ formaldehyde. At this time he was using a Cordis Dow 1.3 disposable artificial kidney sterilised with formalin. The rash disappeared when a disposable artificial kidney (Cordis Dow 1.3) sterilised with ethylene oxide and free of formalin was substituted.

In February 1982 he again developed eczematous dermatitis affecting his hands, arms, and face. He attended the dermatology clinic in December 1982 with obvious dermatitis of the cheeks, eyelids, forehead, and both forearms, particularly the left arm, in which the shunt was situated. Patch testing with the European standard battery again showed a positive reaction to formaldehyde, and he also had a positive reaction to thiuram mix (containing $0.25 \%$ each of tetramethyl thiuram monosulphide, tetraethyl thiuram disulphide, and dipentamethylene thiuram disulphide). ${ }^{1}$ Both these reactions were present at 48 hours and were still positive at 120 hours. There was a weaker positive reaction to carba mix (containing $1 \%$ each of zinc diethyl carbamate, zinc dibutyl carbamate, and diphenyl guanidine). Both these substances are accelerators used to speed up the vulcanisation, or cross linking, of latex to produce rubber. ${ }^{2}$ There was no reaction to the other common rubber accelerator, mercaptobenzothiazole. When the artificial kidney was tested for formaldehyde with both chromotropic acid and Schiff's reagent the results were negative.

We thought it possible that rubber chemicals, to which he was allergic, were being released from the haemodialysis equipment. A different type of disposable artificial kidney (ASAHI AM 10L) was therefore substituted in April 1983, and his dermatitis completely disappeared. When he used the original Cordis Dow dialyser for one dialysis the irritation of his skin returned but there was no visible rash. Patch tests with serum from blood that had passed through the Cordis Dow artificial kidney and components of the apparatus gave negative results.

\section{Comment}

Hollow fibre artificial kidneys are now in common use. They consist of a plastic cylinder about $20 \mathrm{~cm}$ long and $8 \mathrm{~cm}$ in diameter. Running the length of the cylinder are 10000-14000 capillary tubes, through which the blood flows. Their ends are embedded in a rubber 
compound at each end of the cylinder, and the dialysis fluid flows between them via connectors in the cylinder wall.

Dermatitis has been reported in four patients using haemodialysis equipment. ${ }^{3}$ Three of them underwent patch tests, which showed a positive response to thiuram compounds; a further four patients had positive reactions to thiuram on patch testing but no dermatitis. Patch tests with the components of the apparatus gave negative results. Our patient showed a positive reaction to thiuram but did not react to patch tests with components of his equipment.

Hillman et al reported that a plasticiser from a neonatal catheter had been detected in neonatal tissue ${ }^{4}$ and suggested that rubber chemicals are dissolved in the course of haemodialysis to produce sensitisation. We believe that a similar mechanism operated in our patient. Thiuram and carbamate compounds are present in rubber in a concentration of $0 \cdot 125-0 \cdot 30 \%$ and are a common cause of sensitivity to rubber. ${ }^{5}$ They are normally insoluble in water but can be dissolved in acetone, benzene, and carbon tetrachloride. It is of interest that an allergic reaction developed in a patient who had rejected three renal transplants. This suggests that he might have an unusually strong type IV immunological response.

${ }^{1}$ Cronin E. Contact dermatitis. Edinburgh: Churchill Livingstone, 1980.

2 Wilson HTH. Rubber dermatitis. Br 7 Dermatol 1969;81:175-9.

${ }^{3}$ Pennys NS, Edwards LS, Katsikas JL. Allergic contact sensitivity to thiuram compounds in a haemodialysis unit. Arch Dermatol 1976; 112:811-3.

1 Hillman LS, Goodwill SL, Sherman WR. Plasticizer in neonatal tissue after umbilical catheterization. $N$ Engl f Med 1975;292:381-6.

${ }^{5}$ Gaul EI. Results of patch testing with rubber antioxidants and accelerators. F Invest Dermatol $1957 ; \mathbf{2 9}: 105-10$

(Accepted 20 fuly 1983)

Department of Dermatology, Royal infirmary, Edinburgh EH3 9YW P K BUXTON, MRCP, FRCPC, consultant

S M GOING, $M B, M R C P$, registrar

J A A HUNTER, MD, FRCPED, professor

Medical Renal Unit, Royal Infirmary, Edinburgh EH3 9YW

R J WINNEY, MB, FRCPEN, consultant renal physician

\section{Acute hypotensive response to nifedipine added to prazosin in treatment of hypertension}

Nifedipine is a calcium antagonist that is increasingly used in antihypertensive treatment. ${ }^{2}$ Excess hypotension or left ventricular depression was initially thought to be hazardous in patients already receiving beta adrenoceptor blockade, ${ }^{3}$ although the combination is now known to be generally safe. ${ }^{2}$ We report two cases in which administration of nifedipine with prazosin caused an acute hypotensive response; reactions to the two drugs were subsequently studied in eight further patients.

\section{Case reports}

Case 1-A 42 year old man with essential hypertension was being treated with atenolol, prazosin, and a thiazide diuretic, but control was inadequate. A nifedipine placebo capsule was administered one hour after a dose of prazosin $5 \mathrm{mg}$, and no change in blood pressure occurred. Then $10 \mathrm{mg}$ active nifedipine was given sublingually; after 20 minutes his blood pressure had fallen from $200 / 120 \mathrm{~mm} \mathrm{Hg}$ supine and $232 / 124 \mathrm{~mm} \mathrm{Hg}$ standing to $150 / 78 \mathrm{~mm} \mathrm{Hg}$ supine and $88 / 48 \mathrm{~mm} \mathrm{Hg}$ standing (figure). He complained of dizziness and recovered spontaneously. He was twice rechallenged with the nifedipine and prazosin combination, once after six weeks without taking atenolol to exclude the possibility of an adverse interaction between nifedipine and beta adrenoceptor blockade. ${ }^{3}$ On both occasions the initial systolic pressures were over $200 \mathrm{~mm} \mathrm{Hg}$ and the diastolic pressures about $120 \mathrm{~mm} \mathrm{Hg}$. When nifedipine was administered soon after a dose of prazosin standing systolic pressures fell to under $100 \mathrm{~mm} \mathrm{Hg}$ (figure), with spontaneous recovery.

Case 2-A 44 year old man with a history of severe hypertension and unstable angina pectoris, whose supine blood pressure was 200/140 $150 \mathrm{~mm} \mathrm{Hg}$, was being treated with rauwolfia serpentina, methyldopa, and nifedipine all twice daily. He was treated with prazosin $2 \mathrm{mg}$ to reduce his blood pressure, but this was ineffective so the dosage was repeated. The response was considered to be inadequate, and $20 \mathrm{mg}$ nifedipine was administered sublingually. His blood pressure fell rapidly to $110 / 70 \mathrm{~mm} \mathrm{Hg}$ and he was distressed and sweating, with tachycardia and further chest pain. He was kept supine and spontaneous recovery followed.

Other cases-These severe interactions stimulated further studies. Eight patients with uncontrolled hypertension were given prazosin and nifedipine as described above. Mean (SEM) control blood pressures in this group were $210 / 110(7 / 6) \mathrm{mm} \mathrm{Hg}$ supine and $204 / 116(10 / 6) \mathrm{mm} \mathrm{Hg}$ standing. These values were unchanged one hour after administration of prazosin. Twenty minutes after the patients were given nifedipine placebo mean blood pressures were 198/108 (6/3) $\mathrm{mm} \mathrm{Hg}$ supine and $192 / 114(8 / 5) \mathrm{mm} \mathrm{Hg}$ standing. Twenty minutes after administration of active nifedipine pressures were $173 / 96(6 / 5) \mathrm{mm} \mathrm{Hg}$ supine and $168 / 97(8 / 3) \mathrm{mm} \mathrm{Hg}$ standing (figure).

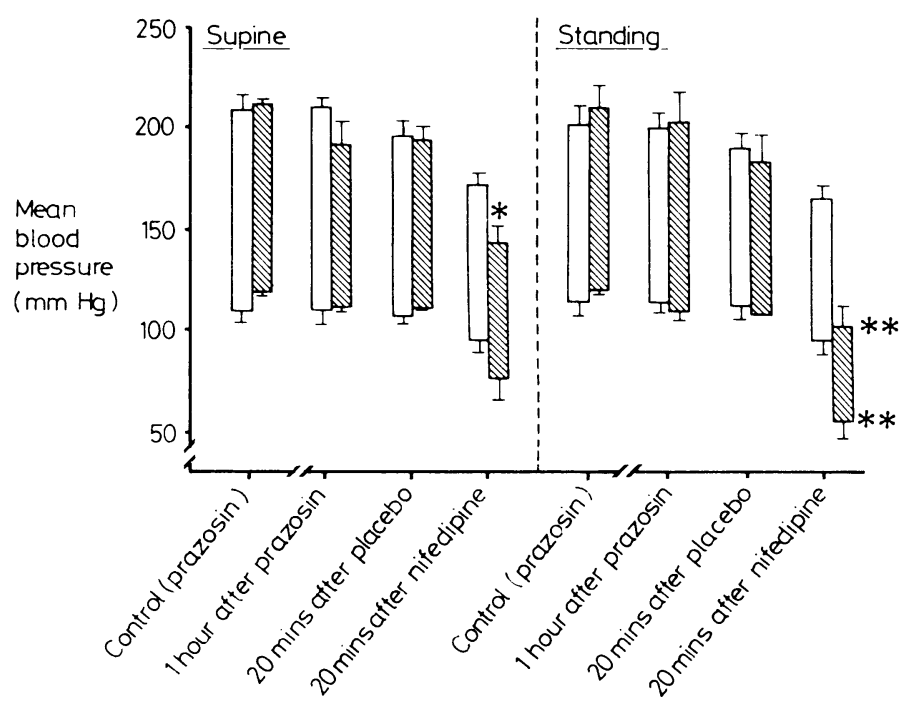

Mean (SEM) blood pressures in eight patients given nifedipine and prazosin (open columns) compared with mean pressures in a patient sensitive to the combination who was challenged on three occasions. ${ }^{*} \mathrm{p}<0.05 ;{ }^{* *} \mathrm{p}<0.005$.

\section{Comment}

We are not aware of studies directed at the possible added hypotensive effects of calcium antagonists such as nifedipine and alpha ${ }_{1}$ antagonists such as prazosin. The fact that two of the 10 patients reported on here showed adverse effects to the combination leads us to suggest that great care should be taken in prescribing additive treatment with these two drugs. When nifedipine is added to prazosin it should be given as a $5 \mathrm{mg}$ dose with the patient recumbent and carefully observed. Conversely, when prazosin is given to patients already receiving nifedipine a test dose of $0.5 \mathrm{mg}$ should be given while the patient is recumbent. Both prazosin and nifedipine are valuable antihypertensive agents, probably acting on different receptors in vascular smooth muscle ${ }^{4}$; This report argues against their combined use except in carefully monitored circumstances.

${ }^{1}$ Guazzi MD, Fiorentine C, Olivari MT, Bastorelli A, Necchi G, Polese A. Short- and long-term efficacy of a Ca-antagonistic agent (nifedipine) combined with methyldopa in the treatment of severe hypotension. Circulation 1980;61:913-9.

2 Opie LH, Jee L, White D. Antihypotensive effect of nifedipine combined with cardioselective beta-adrenergic receptor antagonism by atenolol. Am Heart f 1982;104:606-12.

${ }^{3}$ Opie LH, White DA. Adverse interaction between nifedipine and $\beta$ blockade. Br Med f 1980;281:1462-4.

${ }^{4}$ Van Zwieten PA, Van Meel JCA, de Jonge A, Wilffert B, Timmermans PBMWM. Central and peripheral a-adrenoceptors. $f$ Cardiovasc Pharmacol 1982;4:519-24.

(Accepted 1 August 1983)

Heart Research Unit, Medical School, University of Cape Town, and Hypertension Clinic, Groote Schuur Hospital, Cape Town, South Africa

L D JEE, $M B, C H B$, research registrar

L H OPIE, MD, FRCP, professor

Correspondence to: Professor L H Opie. 